\title{
UTILITY OF QSOFA AND SIRS SCORE IN PREDICTING THE OUTCOME IN PATIENTS WITH SUSPECTED SEPSIS PRESENTING TO EMERGENCY ROOM IN FIRST 24HRS; AN OBSERVATIONAL STUDY
}

\author{
DR. RAMESH ${ }^{1}$.M, DR. IRSHAD AHMED ${ }^{2} \&$ DR. CHANDRASHEKAR A.L ${ }^{3}$ \\ ${ }^{1}$ Associate Professor, Department of Emergency Medicine, PESIMSR, Kuppam, Andhra Pradesh, India \\ ${ }^{2}$ Sr.Resident, Department of Emergency Medicine, PESIMSR ,Kuppam, Andhra Pradesh, India \\ ${ }^{3}$ Professor and Head, Department of Emergency Medicine, PESIMSR ,Kuppam, Andhra Pradesh, India
}

\section{ABSTRACT \\ INTRODUCTION}

Sepsis is most serious illness assessed based on cohort prospective study at population level (WHO2018 report). In past four decades SIRS criteria have been used to assess the disease condition. However, these impideness criteria is not useful for the researcher for inception of new therapy. In Indian context, very limited literature is available to prediction of accurate determinants of qSOFA and SIRS.As for as assessment concern, the present study attempt to correlate the utility of qSOFA and SIRS score in the outcome among patients with suspected sepsis presenting in Emergency Room in the first 24 hours.

\section{METHODS}

An observational time-bound hospital-based perspective study was conducted at Department of Emergency Medicine PESIMSR, Kuppam, and Andhra Pradesh. The study was conducted with a sample size of 150 patients, who presented with features suggestive of sepsis. Study conducted during the period Jan 2018 to Jun 2019. The inclusion and exclusion criteria were employed. Data was collected from pre- tested questionnaires. Data analysis was done by using SPSS statistical software. Descriptive and multiple logistic regression was used to test the hypothetical statements.

\section{RESULTS}

In the present study, mean age of the cases was $45.21 \pm 2.31$ years (IQR 30-60 years; CI95\% 29.85 -62.22 years, odds 5.22 ). Male gender predominated with (57.3\%) with sex ratio was 1:1.30. At the time of presentation (96\%) of cases were showed Heart rate $>90$ beats per minute, (4\%) cases were seen Heart rate of fewer than 90 beats per minute. More than half of the patients (56\%) were Hypotensive at the time of presentation and Tachypnea was (96\%); RR >22 per minutes. Half of the cases were Hyperthermic, and rest were Normothermic, with minority (2.7\%) shows Hypothermia. Only (30\%) of patients were Hypoxic condition. Almost, all three-quarters of Patients had altered sensorium while the rest of the cases were normal GCS. The majority of patients (80\%) cases raised total counts, while leucopoenia (15\%). The Blood Lactate was high in half of the patients; it was seen very high in one quarter and normal in another quarter respectively. Threequarters of patients did not require either Mechanical Ventilator or Vasopressor support. Total (38\%) cases were required more than six days for therapy in ICU and (72\%) of cases were discharged from the hospital while 29(19.33\%) cases were expired within 24 hours of admission, and the remaining cases of 13 (8.66\%) is expired after 24 hours. Half of the patients showed 2 points according to qSOFA, and similar number shows 3 points, according to SIRS. Total (1.3\%) of cases with SIRS and did not satisfy the qSOFA, while only (0.7\%) meet qSOFA criteria. An equal number of patients were shows higher possible scores and found to be statistically insignificant ( $p>0.01$; odds 1.33).There is no satisfactory significant 
correlation between qSOFA and Mortality rate within 24hours

CONCLUSION

Our findings revealed that, the qSOFA is better predictor when compared to SIRS criteria for predicting ventilator-free days and the need for vasopressor supports \& organ dysfunction-free days. Since, SIRS criteria is good predictor on the estimation of mortality rate in emergency situation. These findings should be taken into account and it may helpful for clinicians to advance gain for further insight diagnosis, usefulness of qSOFA had better planning for patient management. KEYWORDS: qSOFA, SIRS, prediction, mortality rate, freedays

Received: Oct 05, 2020; Accepted: Oct 25, 2020; Published: Dec 07, 2020; Paper Id.: IJMPSOCT20203

\section{INTRODUCTION}

The Sepsis remains significant burden of disease in medical research [3]. Various studies, including a recent meta-analysis research findings were estimated annual global incidence of Sepsis is 2.30 millions and mortality was drew up to 0.80 millions [1-2]. It has been known that long-term physical, cognitive, and psychosocial morbidity is associated with survival following sepsis and mortality rate shoot up to 2 years after the intervention [3-6]. Diagnostic criteria that are accurate and definitions have a critical role in the Emergency room, providing basic assessment tools for research beginners and policy makers for implementation of policy. From the literature we studied that, the sepsis is not an pro inflammatory aspects which involves response of anti-inflammatory [16]. In the advent of SIRS criteria sensitivity of predictors shows insufficiently to assess the infected patients at higher risk level when the cases shows complicated .Many literature have cited worldwide, sepsis is viewed organ dysfunction caused by a deregulated infection response [18-20]. In this marginal research gap, we intended to compare qSOFA and SIRS for predicting adverse outcomes of patients with suspicion of sepsis in the Emergency Room.

\section{METHODS}

The prospective study was conducted (besides with time-bound hospital-based observational study) from Jan 2018 to Jun 2019 at Department of Emergency Medicine, PESIMSR, Kuppam, Andhra Pradesh. A total 150 Adult patients presenting with clinical attributes on sepsis, suspected cases were presenting to Emergency Room .All suspected cases were considered for the study relayed upon the primary admission over a period of 18 months [qSOFA and SIRS Criteria calculated].The following inclusion exclusion criteria was employed for recruitment of patients Inclusion Criteria; All consecutive adult patients aged between 18 to 59 years with known suspected cases of Sepsis, Patients satisfy the criteria for sepsis and septic shock based on QSOFA and SIRS scores, Exclusion Criteria; Age <15years; Patients in whom there are technical difficulties in measuring parameters accurately and Patients presenting with a confounding diagnosis along with the primary diagnosis of Sepsis like Acute Coronary Syndrome, Diabetic Ketoacidosis, Burns, Trauma, Patients Requiring Immediate Surgical Intervention. All cases were admitted to Emergency department and evaluated according to Standard protocols and treating Physicians discretions; q SOFA AND SIRS was determined and tabulated accordingly

\section{Ethical issues}

Institutional ethical clearance was obtained in accordance with standard format. The study started at highest accuracy for managing patients with any overlapping flow or recruitment. 


\section{Data Analysis and Statistical Methods}

Collected data was analysed by using SPSS statistical software, Descriptive Statistics and multivariate analysis was done to test the hypothetical results. Data was also represented using appropriate diagrams like a bar diagram, pie diagram, and box plots.

\section{Results}

A total of 150 people were included for the study. The mean age in the study population was $45.13 \pm 1.5$ years with the older age was 82 years. Majority (52\%) population age between 30 to 60 years (IQR 29.31-62.58 years) and (38\%) were > 60 years. Males constituted 57.3(80.0\%) and the remaining 64(42.7\%) were females. Fever (77\%) is the most frequent presenting complaint followed by a cough and difficulty in breathing (65\%) and vomiting and loose stools (24\%), decreased urine output and burning micturition (22\%), altered sensorium (12\%). Among the study population 26 (17.3\%) participants were Business people, 10 (6.7\%) participants were labourer 23(15.3\%) participants were farmers 15(10\%) participants were jobholder $07(4.7 \%)$ participants were retired employee $4(2.7 \%)$ participants were a student and 39 (26\%) homemakers (Table 1.1).

Table 1.1: Significance of demographic variables $(n=150)$

\begin{tabular}{|c|c|c|c|c|c|}
\hline & Age( years) & No $(\%)$ & Odds & CI-95\% & P-value \\
\hline a. & $1-30$ years & $15(10 \%)$ & 0.93 & $8.56-11.22$ & $\mathrm{p}>0.01$ \\
\hline b. & 30-60years & $78(52 \%)$ & 5.63 & $42.01-54.99$ & $\mathrm{P}<0.01$ \\
\hline c. & Above 60 years & $57(38 \%)$ & 8.14 & $31.21-42.33$ & $\mathrm{P}<0.01$ \\
\hline \multicolumn{6}{|c|}{ Gender } \\
\hline & Male & $86(57.30 \%)$ & 0.79 & $53.15-62.89$ & $\mathrm{p}>0.01$ \\
\hline b. & Female & $64(42.70 \%)$ & 0.98 & $40.22-46.58$ & $\mathrm{p}>0.01$ \\
\hline \multicolumn{6}{|c|}{ Occupational Status } \\
\hline a. & Businessman & $26(17.30 \%)$ & 3.65 & $15.17-20.96$ & $\mathrm{P}<0.01$ \\
\hline b. & Labour & $10(6.70 \%)$ & 0.97 & $5.42-7.58$ & $\mathrm{p}>0.01$ \\
\hline c. & Farmers & $23(15.30 \%)$ & 2.55 & $9.63-17.55$ & $\mathrm{P}<0.01$ \\
\hline d. & Home Stay & $26(17.30 \%)$ & 3.01 & $13.15-19.63$ & $\mathrm{P}<0.01$ \\
\hline e. & Job Holder & $15(10.0 \%)$ & 1.25 & $7.85-12.58$ & $\mathrm{P}<0.01$ \\
\hline f. & Retired Employee & $07(4.70 \%)$ & 0.25 & $3.65-6.55$ & $\mathrm{p}>0.01$ \\
\hline g. & Students & $04(2.70 \%)$ & 0.36 & $1.25-3.17$ & $\mathrm{p}>0.01$ \\
\hline h. & House Wife's & $39(26.0 \%)$ & 4.52 & $21.22-27.58$ & $\mathrm{P}<0.01$ \\
\hline
\end{tabular}

SBP/DBP blood pressure was recorded systematically, study found that , out of 150 subjects, 84 cases (56\%) were Hypotensive, $62(41.3 \%)$ cases were Normal and 4 (2.7\%) is Hypertensive. Heart Rate $144(96 \%)$ were $<90$, and 6 (4\%) were $>9$ pulse per minutes; Respiration rate $4.0 \%$ cases were shows normal value and it was seen statistically significant $(\mathrm{p}<0.01) .15(10 \%)$ belongs to below 30 years of age group,78 (52\%) belongs to 30-60 years age group, and 57 (38\%) belongs to above 60 years of age group. 


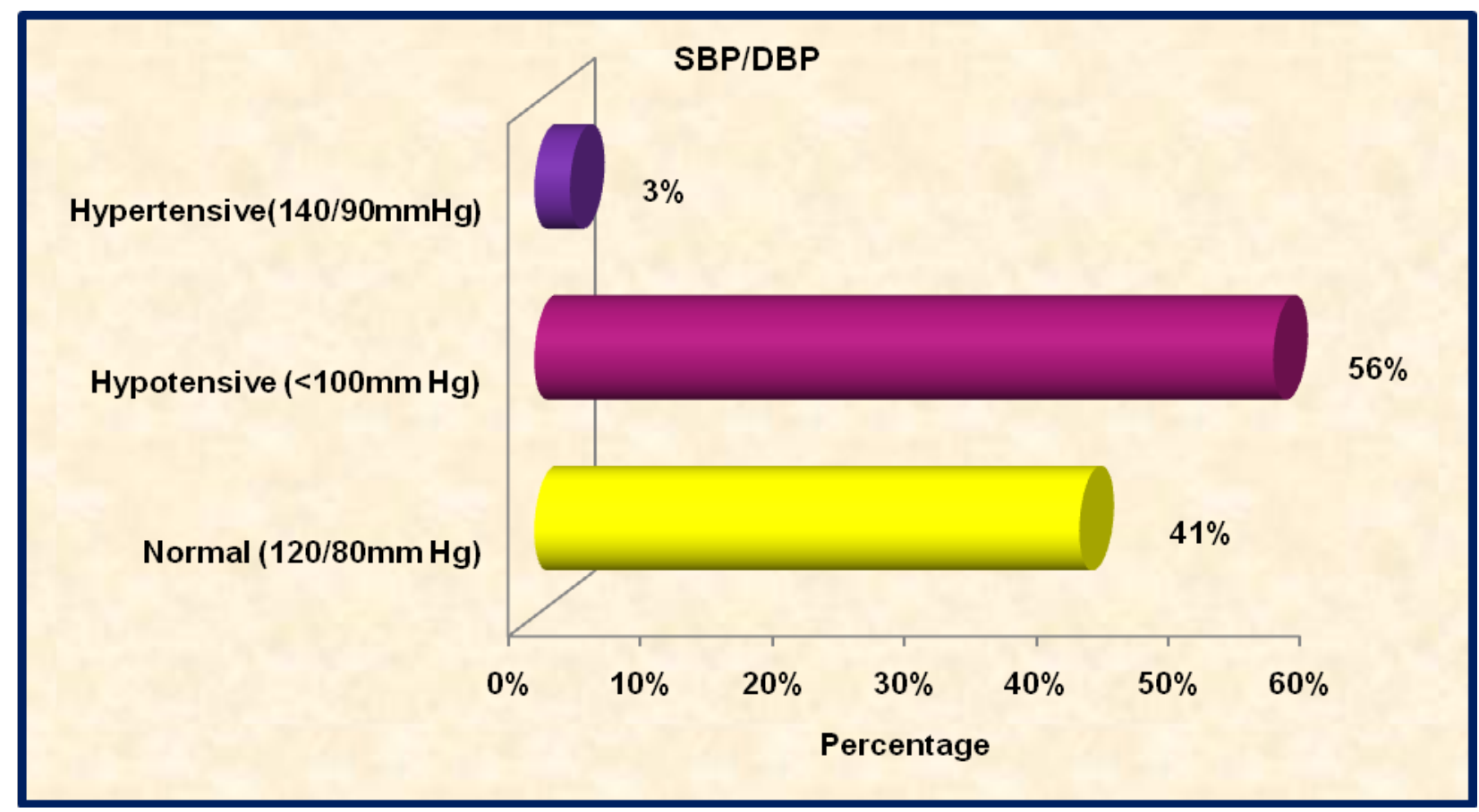

Figure 1.1: SBP/SBP distribution of 150 subjects

Distribution of temperature normal (46.0\%);Hyperthermia (51.30\%) and hypothermia (2.70\%); $\mathrm{SpO} 2>90$ $(70 \%),<90 \quad(30 \%)$; GCS Abnormal (72.\%); Total Count 4000-12000 cells/cumm (15.30\%); >12,000 cells/cumm $(80.0 \%) ;<4000$ cells/cumm (4.70\%), Clinical variable according to the Need of mechanical ventilator, out of 150,108 $(72 \%)$ were No, and $42(28 \%)$ was Yes. Clinical variable according to the Number of ICU Days, out of 150,57 (38\%) were > 6 Days, is 49 (32.7\%) were 3-6 Days, and 44 (29.3\%) were 1-3 Days which includes death within 24 hours. according to the Death \& Discharge, out of 150, 108 (72\%) were Discharged, are 29 (19.3\%) were Death within 24 Hrs, and $13(8.7 \%)$ were Death after 24 Hrs.

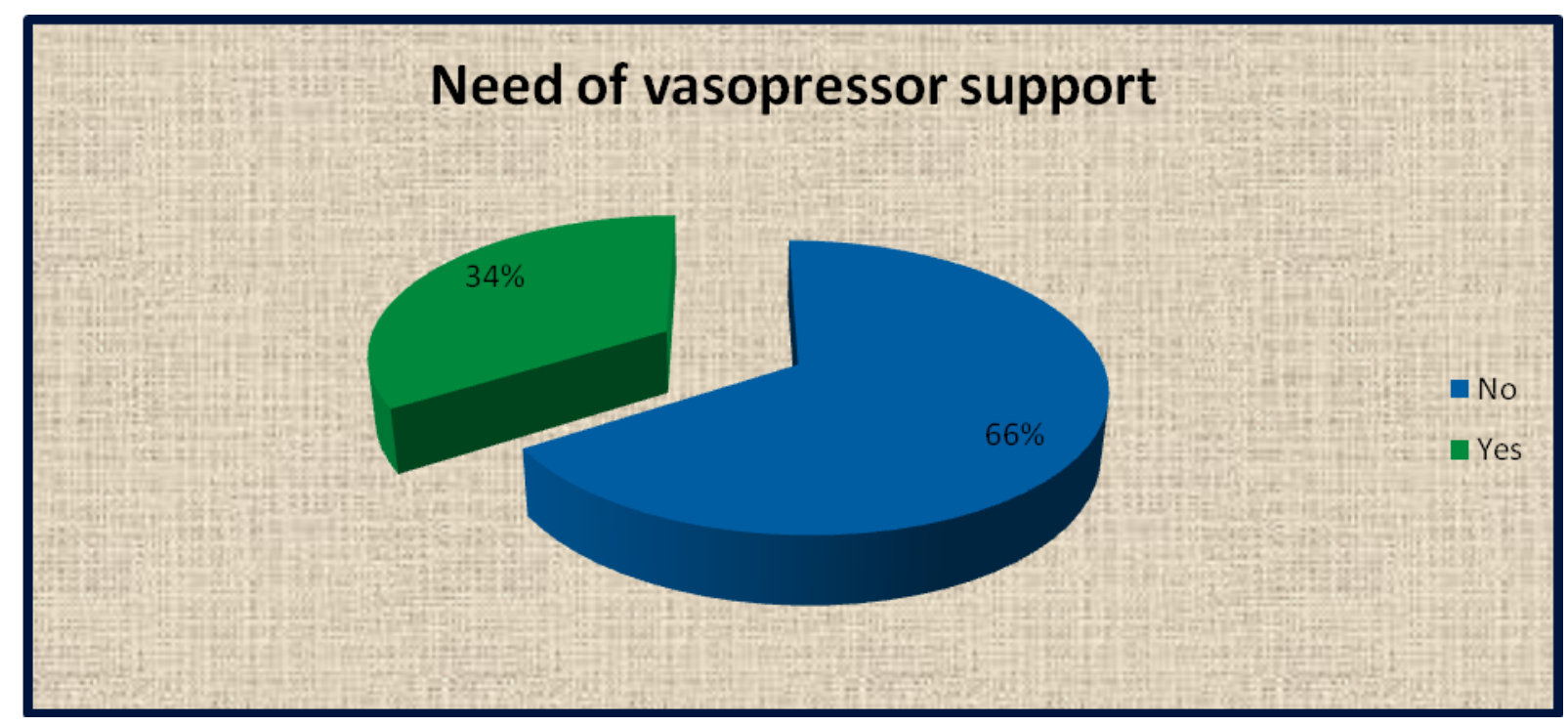

Figure 1.2: Frequency and percentage distribution of Need for vasopressor support

The above table and graph show the Clinical variable according to the Need of vasopressor support, out of 150,99 


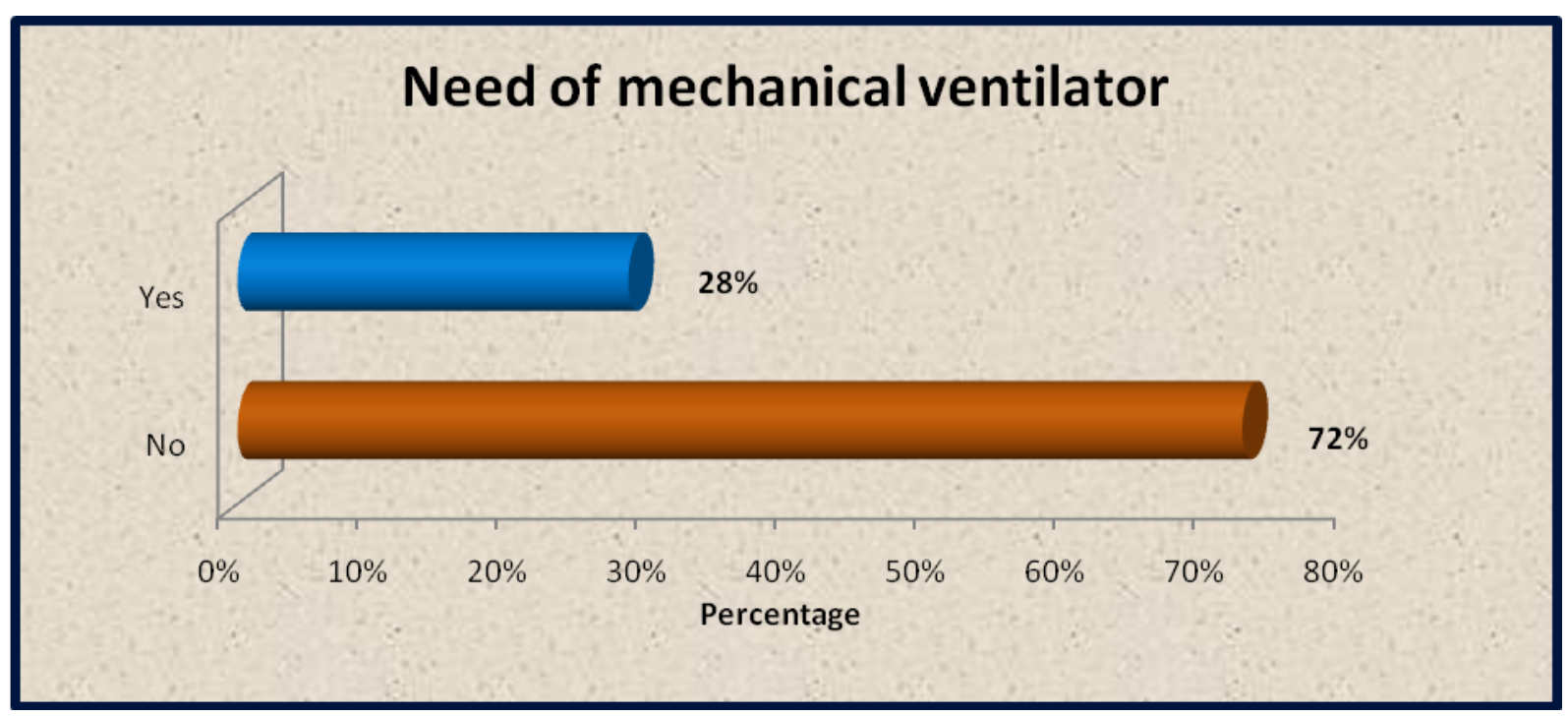

Figure 1.3: Need for mechanical ventilation

Table 1.2: Frequency and percentage distribution of qSOFA score

\begin{tabular}{|c|c|c|c|c|}
\hline \multicolumn{2}{|c|}{ qSOFA Score } & \multicolumn{2}{|c|}{ SIRS } & \multirow[b]{2}{*}{ P-value } \\
\hline Score & No $(\%)$ & Score & No $(\%)$ & \\
\hline 0 & $2(1.30 \%)$ & 1 & $1(0.70 \%)$ & 0.632 \\
\hline 1 & $15(10.0 \%)$ & 2 & $22(14.70 \%)$ & 0.073 \\
\hline 2 & $76(50.70 \%)$ & 3 & $70(46.60 \%)$ & 0.012 \\
\hline 3 & $57(38.0 \%)$ & 4 & $57(38.0 \%)$ & 0.036 \\
\hline
\end{tabular}

From Table 1.2, the able and graph shows the Clinical variable according to the $\mathrm{q}$ SOFA, out of $150,76(50.7 \%)$ were 2 , are $57(38 \%)$ were 3 , are $15(10 \%)$ were 1 . and $2(1.3 \%)$ were 0 .

Table 1.3: shows association of death with qSOFA $(n=150)$

\begin{tabular}{|c|c|c|c|c|c|}
\hline \multirow{3}{*}{ q SOFA } & \multicolumn{4}{|c|}{ Death \& Discharge } & Chi-square \\
\hline & Discharged & \multicolumn{2}{|c|}{ Death within 24 Hrs } & $\begin{array}{l}\text { Death after } 24 \text { Hrs and } \\
\text { during the hospital stay }\end{array}$ & Results \\
\hline & $\mathbf{F}$ & $\mathbf{F}$ & & $\mathbf{F}$ & \multirow{5}{*}{$\begin{array}{c}\text { Not } \\
\text { Significan } \\
t\end{array}$} \\
\hline 0 & $2(1.9 \%)$ & $0(0.0 \%)$ & & $0(0.0 \%)$ & \\
\hline 1 & $11(10.20 \%)$ & $2(6.90 \%)$ & & $2(15.40 \%)$ & \\
\hline 2 & $58(53.70 \%)$ & $10(34.50 \%)$ & & $8(61.50 \%)$ & \\
\hline 3 & $37(34.30 \%)$ & $17(58.60 \%)$ & & $3(23.10 \%)$ & \\
\hline
\end{tabular}

The above Table 1.3 shows that, the association of 150 samples of q SOFA, analysis was employed to assess the significance relation between Death \& Discharge associated q SOFA score, and it was found to be insignificant at $\mathrm{P}>0.05$.

Table: 1.4: Shows association of death \& discharge with SIRS $(n=150)$

\begin{tabular}{|c|c|c|c|c|c|c|c|c|}
\hline \multirow{3}{*}{ SIRS } & \multicolumn{6}{|c|}{ Death \& Discharge } & \multicolumn{2}{|c|}{ Chi-square } \\
\hline & \multicolumn{2}{|c|}{ Discharged } & \multicolumn{2}{|c|}{ Death within 24 Hrs } & \multicolumn{2}{|c|}{ Death after 24 Hrs } & P-value & Results \\
\hline & $\mathbf{F}$ & $\%$ & $\mathbf{F}$ & $\%$ & $\mathbf{F}$ & $\%$ & \multirow[b]{2}{*}{$* 0.028$} & \multirow[b]{2}{*}{ Significant } \\
\hline 1 & 0 & $0 \%$ & 0 & $0 \%$ & 1 & $7.7 \%$ & & \\
\hline
\end{tabular}




\begin{tabular}{|l|l|l|l|l|l|l|l|l|}
\hline 2 & 16 & $14.8 \%$ & 6 & $20.7 \%$ & 0 & $0 \%$ & & \\
\cline { 1 - 7 } & 50 & $46.3 \%$ & 12 & $41.4 \%$ & 8 & $61.5 \%$ & & \\
\hline $\mathbf{4}$ & 42 & $38.9 \%$ & 11 & $37.9 \%$ & 4 & $30.7 \%$ & & \\
\hline
\end{tabular}

Above Table 1.4 revealed that, the 150 samples with their SIRS, Univariate analysis was used to determine the relation between death \& discharge of SIRS score, and it was showed to be statistically significant at $\mathrm{P}<0.05$.

\section{DISCUSSIONS}

Sepsis is significant cause of morbidity and mortality globally [15]. An infinite number of cases get admitted annually at worldwide, because sepsis is leading to a high number of deaths (30\%) mortality absurd annually [25]. Majority of the cases who suffering from sepsis is admitted to the hospital in emergency department [6]. An early identification and management of sepsis by effective treatment and management to lower mortality rate [29-30]. An effective strategy for improving sepsis management to detect the manipulation of treatment strategies is need base in existing situation, because high rate of mortality recorded in emergency room globally. A newer tool is important to magnificent the death rate , Eamon P Raith et al. studied the prognostic accuracy of the SOFA score along with the SIRS Criteria and qSOFA Score for In-hospital mortality among adults with Suspected infections in the Emergency room [21]. Ari Moscowitz et al. studied qSOFA and SIRS as Predictors of Critical Care Intervention among Patients with Suspected Infection [22]. Jianjun Jiang et al. studied Head-to-head comparison of qSOFA and SIRS criteria in predicting the mortality of infected patients in the emergency department [13].The mean age among the study population was $45 \pm 15$, with the oldest being 82 years. The majority $(52 \%)$ of the study population was between 30 to 60 years, and (38\%) were $>60$ years. In a study done by April et al. 2017. Total 42, the median age was 67 years. In a study by Askim et al. 45, the mean age was $62 \pm 12$ years. In another study by Finkelstein et al., who have assessed a Comparison of the capacity of discrimination of qSOFA versus SIRS criteria for predicting in-hospital deaths and, the mean age was 64 years. In a study by Kim et al who have assessed the Predictive Performance of qSOFA as a screening tool for sepsis, mortality, and ICU admission, the mean age of the study population, was in there were 54 years with the range of 45-66 years which is slightly higher than our study. In another study by Bhat et al, the mean age of the subjects was $63 \pm 17.9$ years. In another study by Tirado-Sanchez et al., the mean age of patients with severe sepsis was $31.27 \pm 8.21$ years. The low mean age in the current study might be a due chance. Another possibility is that due to the poor economic conditions of the rural population, everyone cannot afford tertiary level care. The earning members of the family will be given priority, and they are preferentially taken to higher levels of care [1-9]. This leads to inappropriately high levels of middle-aged populations in the samples from tertiary care hospitals. Among the study population, demographic variable according to the age group of 150 samples, among them $15(10 \%)$ belongs to below 30 years of age group,78 (52\%) belongs to 30-60 years age group, and 57 (38\%) belongs to above 60 years of age group. In the current study, Males constituted 57.3(86\%) of the study population, and the remaining $42.7 \%$ (64) were females. In a study by Henning et al. performance of qSOFA in predicting in-hospital mortality, the proportion of males and females was similar ( $50 \%$ ), as compared to the male preponderance in our study. In a study by Hwang et al. the proportion of males (56.4\%), which is almost similar to the current study. In a study by forwarding et al. Comparison of prognostic performance of qSOFA, SIRS, and SK criteria, the proportion of males and females (53.77\%) and (44.23\%) respectively [30,31]. In a study by Quinten et al., males constituted (56.1\%) of the study population. Overall most of the studies are having a male preponderance in case distribution, which is reflected in the current study. Two explanations can be given for this preponderance. One, males usually go out to work and socialize, making them prone to infections, which 
are sometimes virulent. Second, in rural areas, males are given more importance and are preferentially brought to higher levels of care. In the current study population the Heart Rate, out of 150, $144(96 \%)$ were $<90$, and $6(4 \%)$ were $>90$. To the SBP/DBP, out of 150, 84 (56\%) were Hypotensive, are 62 (41.3\%) were Normal, and 4 (2.7\%) were Hypertensive. The Target Map, out of 150, 83 (55.3\%) were abnormal, and 67 (44.7\%) were Normal. The Respiratory Rate, out of 150, 144 (96\%) were abnormal, and 6 (4\%) were Normal. In Temperature, out of 150, 77 (51.3\%) were Hyperthermia, are 69 (46\%) were Normal, and 4 (2.7\%) were Hypothermia. The GCS, out of 150, 108 (72\%) were Abnormal, and 42 (28\%) were Normal. The Total Count, out of 150, $120(80 \%)$ were $>12,000$, are $23(15.3 \%)$ were 4000-12000, and 7 (4.7\%) were $<4000$. In this study Need of vasopressor support, out of 150, 99 (66\%) required vasopressor support, and 51 (34\%) doesn't need and to the mechanical ventilator, out of 150, 108 (72\%) were kept on mechanical ventilator support, and 42 (28\%) were not. In mortality, out of 150, 108 (72\%) were Discharged, are 29 (19.3\%) were Death within 24 Hrs, and 13 (8.7\%) were Death after $24 \mathrm{Hrs}$. The study, comprised of high-mortality (19\%) patients within $24 \mathrm{hrs}$ and 9\% after $24 \mathrm{hrs,}$ $72 \%$ of patients discharged after prolonged ICU stay. In the current study out of 150 patients, One hundred and forty-nine (99\%) included patients were admitted to the ICU within less than 24 hours after their presentation in the emergency department, while the remaining one patient was hospitalized in the wards for more than 24 hours and then shifted to ICU.

\section{CONCLUSIONS}

Summing of the results concludes that, the qSOFA better criteria when compared to SIRS. These findings should be taken into account and may useful for clinicians to gain further insight diagnosis and especially useful for the qSOFA score assessment and better planning for management of cases.

\section{REFERENCES}

1. Eli J et al. Jones-Comparison of qSOFA and SIRS for predicting adverse outcomes of patients with suspicion of sepsis outside the intensive care unit-Critical Care (2017) 21:73

2. HHS Public Access Author manuscript Third International consensus Definition for Sepsis and septic shock-JAMA 2016 Feb23- 215 .

3. Bone RC. The pathogenesis of sepsis. Ann Intern Med. 1991;115:457-69. doi: 10.7326/0003-4819-115-6-457.

4. AL-ANSARI, WALEED IBRAHEEM ALI, ALI SHAWKI, and THURA HIKMAT. "THE EFFECTIVENESS OF TIGECYCLINE IN MULTIDRUG RESISTANT INFECTIONS IN INTENSIVE CARE UNIT." International Journal of Medicine and Pharmaceutical Science 7.3 (2017): 13-20.

5. Tusgul et al. Scandinavian Journal of Trauma, Resuscitation and Emergency Medicine Low sensitivity of qSOFA, SIRS criteria and sepsis definition to identify infected patients at risk of complication in the pre-hospital setting and at the emergency department triage-2017) 25:108

6. Christopher W, Seymour MD, et al Assessment of Clinical Criteria for Sepsis For the Third International Consensus Definitions for Sepsis and Septic Shock (Sepsis-3); JAMA February 23, 2016

7. Sepsis 2018: Definitions and Guideline Changes. Volume 19, Number 2, 2018 Mary Ann Liebert, Inc.DOI: $10.1089 /$ sur.2017.278

8. Gogoi, Sophia M., UMARAM TAMULY, and LAISHRAM SANATHOI KHUMAN. "Prevalence of Sub-Clinical Mastitis in Areas Around Lakhimpur Town of Assam." International Journal of Agricultural Science and Research (IJASR) 7.1 (2017): 501-508. 
9. Balk RA. Severe sepsis and septic shock. Definitions, epidemiology, and clinical manifestations. Crit Care Clin. 2000;16:17992. doi: 10.1016/S0749-0704(05)701068.

10. Severity Scoring Systems: Tools for the Evaluation of Patients and Intensive Care Units Rui P.Moreno, Philipp G.H. Metnitz, in Critical Care Medicine (Third Edition), 2008.

11. Askim A, et al Poor performance of quick-SOFA (qSOFA) score in predicting severe sepsis and mortality - a prospective study of patients admitted with infection to the emergency department. Scand J Trauma Resusc Emerg Med. 2017;25(1):56.

12. Al-Dahmoshi, HUSSEIN OLEIWI MUTTALEB. "Molecular Study of Extend Spectrum $\beta$-Lactamases among Extraintestinal Enterobacter cloacae Recovered From Patients with Cauti, Hilla-Iraq." International Journal of Medicine and Pharmaceutical 4.4 (2014): 13-26.

13. Kristina E. Rudd, et al Association of the Quick Sequential (Sepsis-Related) Organ Failure Assessment (qSOFA) Score With Excess Hospital Mortality in Adults With Suspected Infection in Low- and Middle-Income Countries -. JAMA June 5, 2018

14. Churpek MM, Snyder A, Han X, et al. qSOFA, SIRS, and early warning scores for detecting clinical deterioration in infected patients outside the ICU. Am J Respir Crit Care Med 2017;195.

15. Lisa A. Dykes, Shanon et al J Contrasting qSOFA and SIRS Criteria for Early Sepsis Identification in a Veteran Population .March 2019

16. Mustafá, M. U. R. T. A. Z. A., S. Yusof, and M. U. H. A. M. M. A. D. Iftikhar. "Osteomyelitis: pathogenesis, clinical and therapeutic challenge." Int J Med Pharma Sci 4 (2014): 9-18.

17. Jianjun Jiang et al Head-to-head comparison of qSOFA and SIRS criteria in predicting the mortality of infected patients in the emergency department: a meta-analysis -2018,26-56.

18. Balk RA, Bone RC. The septic syndrome. Definition and clinical implications. Crit Care Clin. 1989;5:1-8.

19. Izumi Nakayama et al Mortality and detailed characteristics of pre-ICU qSOFA-negative patients with suspected sepsis: an observational study -2018

20. NIH Public Access Author Manuscript Annu Rev Pathol. Author manuscript; available in PMC 2013 June 17. Published in final edited form as: Annu Rev Pathol. 2011 ; 6: 19-48. doi:10.1146/annurev-patho.

21. The American Journal of Pathology, Vol. 170, No. 5, May 2007. Biological Perspectives Pathophysiology of Sepsis-Daniel G. Remick, M.D.

22. Jae-Uk Song et al, Performance of the quick Sequential (sepsis-related) Organ Failure Assessment score as a prognostic tool in infected patients outside the intensive care unit: a systematic review and meta-analysis- 2018.

23. Freuad et al Prediction of 28-days mortality with sequential organ failure assessment (SOFA), quick SOFA (qSOFA) and systemic inflammatory response syndrome (SIRS) - A retrospective study of medical patients with acute infectious disease2019

24. Najla Lemachatti et al Prognostic Accuracy of Sepsis-3 Criteria for In-Hospital Mortality Among Patients With Suspected Infection Presenting to the Emergency Department-2017

25. Eamon P. Raith, Prognostic Accuracy of the SOFA Score, SIRS Criteria, and qSOFA Score for In-Hospital Mortality Among Adults With Suspected Infection Admitted to the Intensive Care Unit-2017.

26. Ari Moskowitz, HHS Public Access Author manuscript Crit Care Med. Author manuscript; qSOFA and SIRS as Predictors of Critical Care Intervention among Patients with Suspected Infection- November 2017 
27. Martin M Mitchell et al qSOFA does not replace SIRS in the definition of sepsis-2016

28. S.W. van der Woude*, Classifying sepsis patients in the emergency department using SIRS, qSOFA or MEWS-May 2018

29. Konrad Reinhart et al New Approaches to Sepsis: Molecular Diagnostics and Biomarkers,

30. [Paul E. Marik SIRS, qSOFA and new sepsis definition-Division of Pulmonary and Critical Care Medicine.2017 586-596

31. http://www.admitologist.com/wp-content/uploads/2015/12/Sepsis-Info.jpg qSOFA and SIRS: Alex Ireland, MD (NUEM PGY3) Edited by: Kim Iwaki, MD NUEM Alum '18 Expert commentary by: Benjamin Schnapp, MD.

32. Haydar S et al Comparison of qSOFA score and SIRS criteria as screening mechanisms for emergency department sepsis. 2017 Jul 6.

33. Rodrigo Serafim, et al A Comparison of the Quick-SOFA and Systemic Inflammatory Response Syndrome Criteria for the Diagnosis of Sepsis and Prediction of Mortality. A Systematic Review and Meta-Analysis- March 2018 Volume 153, Issue 3, Pages 646-655

34. Serafim R, Gomes JA, Salluh J, Póvoa P, A Comparison of the Quick-SOFA and Systemic Inflammatory Response Syndrome Criteria for the Diagnosis of Sepsis and Prediction of Mortality: A Systematic Review and Meta-Analysis. Chest. 2018 Mar;153(3):646-655. doi: 10.1016/j.chest.2017.

35. Remi Neviere, MD, Polly E Parsons, MD Sepsis syndromes in adults: Epidemiology, definitions, clinical presentation, diagnosis, and prognosis.

36. Fleischmann C, Scherag A, Adhikari NK, et al. Assessment of Global Incidence and Mortality of Hospital-treated Sepsis. Current Estimates and Limitations. Am J Respir Crit Care Med 2016; 193:259.

37. Blanco J, Muriel-Bombín A, Sagredo V, et al. Incidence, organ dysfunction and mortality in severe sepsis: a Spanish multicentre study. Crit Care 2008; 12:R158.

38. Harrison DA, Welch CA, Eddleston JM. The epidemiology of severe sepsis in England, Wales and Northern Ireland, 1996 to 2004: secondary analysis of a high quality clinical database, the ICNARC Case Mix Programme Database. Crit Care 2006; 10:R42.

39. Danai P, Martin GS. Epidemiology of sepsis: recent advances. Curr Infect Dis Rep 2005; 7:329.

40. Kadri SS, Rhee C, Strich JR, et al. Estimating Ten-Year Trends in Septic Shock Incidence and Mortality in United States Academic Medical Centers Using Clinical Data. Chest 2017; 151:278.

41. Rhee C, Dantes R, Epstein L, et al. Incidence and Trends of Sepsis in US Hospitals Using Clinical vs Claims Data, $2009-2014$. JAMA 2017; 318:1241.

42. Serafim R, Gomes JA, Salluh J, Póvoa P. A Comparison of the Quick-SOFA and Systemic Inflammatory Response Syndrome Criteria for the Diagnosis of Sepsis and Prediction of Mortality: A Systematic Review and Meta-Analysis. Chest 2018; 153:646.

43. Walkey AJ, Wiener RS, Lindenauer PK. Utilization patterns and outcomes associated with central venous catheter in septic shock: a population-based study. Crit Care Med 2013; 41:1450.

44. Kaukonen KM, Bailey M, Suzuki S, et al. Mortality related to severe sepsis and septic shock among critically ill patients in Australia and New Zealand, 2000-2012. JAMA 2014; 311:1308.

45. McPherson D, Griffiths C, Williams M, et al. Sepsis-associated mortality in England: an analysis of multiple cause of death data from 2001 to 2010. BMJ Open 2013; 3. 
46. Angus DC, Kelley MA, Schmitz RJ, et al. Caring for the critically ill patient. Current and projected workforce requirements for care of the critically ill and patients with pulmonary disease: can we meet the requirements of an aging population? JAMA 2000; 284:2762.

47. Uslan DZ, Crane SJ, Steckelberg JM, et al. Age- and sex-associated trends in bloodstream infection: a population-based study in Olmsted County, Minnesota. Arch Intern Med 2007; 167:834.

48. Pop-Vicas A, Tacconelli E, Gravenstein S, et al. Influx of multidrug-resistant, gram-negative bacteria in the hospital setting and the role of elderly patients with bacterial bloodstream infection. Infect Control Hosp Epidemiol 2009; 30:325.

49. Klotz SA, Chasin BS, Powell B, et al. Polymicrobial bloodstream infections involving Candida species: analysis of patients and review of the literature. Diagn Microbiol Infect Dis 2007; 59:401.

50. Annane D, Bellissant E, Cavaillon JM. Septic shock. Lancet 2005; 365:63.

51. Singer M, Deutschman CS, Seymour CW, et al. The Third International Consensus Definitions for Sepsis and Septic Shock (Sepsis-3). JAMA 2016; 315:801.

52. Shankar-Hari M, Phillips GS, Levy ML, et al. Developing a New Definition and Assessing New Clinical Criteria for Septic Shock: For the Third International Consensus Definitions for Sepsis and Septic Shock (Sepsis-3). JAMA 2016; 315:775. 